\title{
QUAIS AS IMPLICAÇÕES PARA O FORTALECIMENTO DA IDENTIDADE NEGRA NO CONTEXTO DA EDUCAÇÃO SUPERIOR?
}

\author{
WHAT ARE THE IMPLICATIONS FOR STRENGTHENING BLACK IDENTITY IN \\ THE CONTEXT OF HIGHER EDUCATION?
}

\section{¿CUÁLES LAS IMPLICACIONES PARA EL FORTALECIMIENTO DE LA IDENTIDAD NEGRA EN EL CONTEXTO DE LA EDUCACIÓN SUPERIOR?}

\author{
Eugenia Portela de Siqueira Marques \\ Universidade Federal da Grande Dourados - Brasil
}

Maria Aparecida Pereira dos Santos Ribeiro

Coordenadoria Regional de Educação de Naviraí - Brasil

\begin{abstract}
Resumo: O objetivo desse artigo é discutir as implicações que o acadêmico negro encontra para estar fortalecendo sua identidade de forma positiva ou não. Delimitou-se na questão norteadora: Quais as implicações para o fortalecimento da identidade negra no contexto da educação superior? Traz resultados da pesquisa de mestrado, em que utilizou-se da pesquisa bibliográfica, análise documental e pesquisa de campo. Para a coleta de dados foram utilizados a entrevista estruturada aplicados a seis acadêmicos negros cotistas de diferentes cursos de graduação ingressantes no período de 2013 a 2016 e questionário on line aplicados a ingressantes cotistas do mesmo período. Nos depoimentos dos participantes da pesquisa, notamos que, quando os acadêmicos têm envolvimento com ações que discutem a temática da população negra, grupos de estudos, disciplinas referentes às relações étnicoraciais, PIBIC e PIVIC, eles apresentam uma identidade fortalecida no espaço universitário.
\end{abstract}

Palavras-Chave: Identidade negra. Educação superior. Ações afirmativas

\begin{abstract}
The purpose of this article is to discuss the implications that the black academician finds to be strengthening his or her identity positively or not. It was delimited in the guiding question: What are the implications for the strengthening of the black identity in the context of higher education? It brings results of the master's research, in which it was used the bibliographic research, documentary analysis and field research. For the data collection, a structured interview was applied to six black scholars from different undergraduate courses from 2013 to 2016 and on-line questionnaire applied to quotaholders in the same period. In the testimonies of the research participants, we noticed that, when academics are involved in actions that discuss the theme of the black population, study groups, disciplines related to ethnic-racial relations, PIBIC and PIVIC, they present a strengthened identity in university space.
\end{abstract}

Keywords: Black identity. College education. Affirmative actions 
Resumen: El objetivo de este artículo es discutir las implicaciones que el académico negro encuentra para estar fortaleciendo su identidad de forma positiva o no. Delimitación en la cuestión orientadora: ¿Cuáles son las implicaciones para el fortalecimiento de la identidad negra en el contexto de la educación superior? Trae resultados de la investigación de maestría, en que se utilizó de la investigación bibliográfica, análisis documental y investigación de campo. Para la recolección de datos fueron utilizados la entrevista estructurada aplicados a seis académicos negros cotistas de diferentes cursos de graduación ingresantes en el período de 2013 a 2016 y cuestionario on line aplicados a ingresantes cotistas del mismo período. En los testimonios de los participantes de la investigación, notamos que cuando los académicos participan con acciones que discuten la temática de la población negra, grupos de estudios, disciplinas referentes a las relaciones étnico-raciales, PIBIC y PIVIC, ellos presentan una identidad fortalecida en el espacio universitario.

Palabras clave: Identidad negra. Educación universitaria. Acciones afirmativas

\section{Introdução}

A democratização do ensino superior contribuiu para mudar o cenário das universidades públicas. Destacamos o sistema de cotas que foi introduzido pela lei 12.711/2012 que determina a reserva de vagas para a população negra.

Neste contexto discutimos o fortalecimento da identidade negra com o acesso nesse espaço hegemonicamente branco com uma cultura monocultural e uma pedagogia eurocêntrica.

Neste artigo trazemos parte da pesquisa: O fortalecimento da identidade negra no contexto da educação superior: um olhar sobre os negros ingressantes pelo sistema de cotas raciais nos cursos de graduação da UFGD para refletir que as políticas de acesso promoveram uma mudança no perfil dos jovens que ingressam na educação superior, mas não promoveram mudanças na cultura acadêmica, no currículo, nos aspectos que serão determinantes ao êxito ou fracasso dos acadêmicos (MARQUES, 2016, p. 1084).

\section{A importância da democratização da educação superior e as ações afirmativas e suas contribuições para a população negra no Brasil}

A democratização do acesso à educação superior representa um avanço significativo. Com ampliação e democratização do acesso realizada no governo de Luiz Inácio Lula da Silva foram efetivadas as seguintes medidas: a educação à distância; a Universidade Aberta do Brasil, a introdução de cotas no sistema público e o PROUNI, nas IES privadas. 
Destacamos o governo de Dilma Rousseff que trouxe a implementação do sistema de cotas para as universidades públicas com a lei 12.711/2012 que prevê em cada instituição federal de ensino superior as vagas serão preenchidas, por curso e turno, por autodeclarados pretos, pardos e indígenas, em proporção no mínimo igual à de pretos, pardos e indígenas na população da unidade da federação onde está instalada a instituição, segundo os critérios do IBGE. (BRASIL, 2012).

O debate sobre as Políticas afirmativas no cenário brasileiro ficou mais fortalecido após a III Conferência Mundial Contra o Racismo: A Xenofobia e Formas Correlatas de Intolerância, realizada em Durban, África do Sul. A mesma exprimia entre outras a necessidade de "ações afirmativas ou medidas de ação positivas, para promoverem o acesso de grupos de indivíduos que são ou podem vir a ser vítimas de discriminação racial”. 1

Existem vários conceitos de políticas afirmativas, assim adotamos o conceito de Gomes que sinaliza,

Um conjunto de políticas públicas e privadas de caráter compulsório, facultativo ou voluntário, concebidas com vistas ao combate à discriminação racial, de gênero, por deficiência física e de origem nacional, bem como para corrigir ou mitigar os efeitos presentes da discriminação praticada no passado, tendo por objetivo a concretização do ideal de efetiva igualdade de acesso a bens fundamentais como a educação e o emprego (...). Em síntese, trata-se de políticas e de mecanismos de inclusão concebidos por entidades públicas, privadas e por órgãos dotados de competência jurisdicional, com vistas à concretização de um objetivo constitucional universalmente reconhecido - o da efetiva igualdade de oportunidades a que todos os seres humanos têm direito. (2001, p.27).

Neste contexto notamos que a política afirmativa é reconhecida e utilizada como um mecanismo de inclusão de grupos que estão à margem em determinadas situações. Dessa forma, elencamos alguns contextos em que as políticas afirmativas foram adotadas no Brasil.

A primeira iniciativa foi realizada em 1943, por Getúlio Vargas, quando aprovou o Decreto-lei 5.452/43, a Consolidação das leis do trabalho (CLT), em cujo artigo 354 especifica sobre ser uma política afirmativa.

Art. 354 - A proporcionalidade será de $2 / 3$ (dois terços) de empregados brasileiros, podendo, entretanto, ser fixada proporcionalidade inferior, em atenção às circunstâncias especiais de cada atividade, mediante ato do Poder

\footnotetext{
${ }^{1}$ III Conferência Mundial contra o Racismo, Discriminação Racial, Xenofobia e Intolerância Correlata, (2001). Declaração de Durban e plano de ação. Traduzido em língua portuguesa. Brasília: Fundação Cultural Palmares/Ministério da Cultura, p. 68.
} 
Executivo, e depois de devidamente apurada pelo Departamento Nacional do Trabalho e pelo Serviço de Estatística de Previdência e Trabalho a insuficiência do número de brasileiros na atividade de que se tratar. (BRASIL. CLT, 1943).

Em 1968, o Congresso instituiu a Lei ${ }^{\circ} 5.465 / 68$, a chamada Lei do boi, que disciplinou o preenchimento de vagas nos estabelecimentos de ensino agrícola. $\mathrm{O}$ artigo $1 .^{\circ}$ da referida Lei in verbis dispõe que:

Art. $1^{\circ}$ Os estabelecimentos de ensino médio agrícola e as escolas superiores de Agricultura e Veterinária, mantidos pela União, reservarão, anualmente, de preferência, 50\% (cinquenta por cento) de suas vagas a candidatos agricultores ou filhos destes, proprietários ou não de terras, que residam com suas famílias na zona rural, e 30\% (trinta por cento) a agricultores ou filhos destes, proprietários ou não de terras, que residam em cidades ou vilas que não possuam estabelecimentos de ensino médio (BRASIL, 1968).

Destacamos que, além das práticas elencadas acima, em outros momentos o Estado adota políticas afirmativas, como afirma Marques (2010, p. 78), que “a sociedade brasileira esquece ou ignora outras iniciativas existentes que reconhecem o direito à diferença de tratamento legal para diversos grupos". Ou seja, as ações afirmativas não foram aplicadas no Brasil apenas com a finalidade de buscar a igualdade racial, mas também em diferentes momentos foram aplicadas para garantir a equidade, a igualdade material, considerando-se que a igualdade formal, preconizada em leis, nem sempre é concretizada.

As ações afirmativas para os negros na educação superior tem deixado em evidencia a mudança de cenários num espaço antes ocupado apenas por branco. Como bem sinaliza em entrevista o ex- coordenador do NEAB na pesquisa: $\mathrm{O}$ fortalecimento da identidade negra no contexto da educação superior: um olhar sobre os negros ingressantes pelo sistema de cotas raciais nos cursos de graduação da UFGD,

[...] as cotas étnico-raciais talvez não façam tanta diferença nos cursos menos concorridos, mas nos cursos mais concorridos elas são importantes, porque criam um percentual a ser atingido para que pelo menos naquele espaço acadêmico haja uma maior representação étnico-racial. É importante que os negros e indígenas entrem nas licenciaturas, mas também é importante que se formem engenheiros, médicos, advogados. $\mathbf{E}$ as cotas étnico-raciais, pelo menos no momento, talvez sejam fundamentais para mudar a representação desses grupos nesses cursos, ou ampliar a diversidade. (AGUIAR, 2016, Grifos nossos).

Com a mudança, ainda que pequena notamos que a diversidade étnica racial ganha espaço e com isso novos desafios para que não fique apenas no acesso, mas se faz necessário 
que tenhamos políticas que garanta a sua permaneça até a conclusão do curso. Tais políticas precisam exercer o seu papel como pontua Heringer,

As políticas de permanência devem ser pensadas para todo e qualquer estudante universitário, enquanto as políticas de assistência se destinam àqueles em situação de maior vulnerabilidade, vivenciando situações que possam comprometer sua permanência, incluídas aí as dificuldades de ordem financeira. (2013, p.27-28).

A autora ainda faz uma afirmação muito apropriada que a universidade precisa levar em consideração, "na prática e nos diferentes arranjos institucionais para a implantação destas políticas, as ações de permanência e assistência estudantil são integradas, às vezes, superpostas ou mesmo confundidas”. (2013 p.28).

Concordando com a mesma em nossa pesquisa observamos a dificuldade dos alunos cotistas em participar do Programa de Assistência estudantil como podemos averiguar nos depoimentos a seguir:

Eu tenho o Cartão do Auxílio Transporte, que tem subsídio no pagamento da tarifa. Referente à bolsa permanência e ao vale alimentação, eu precisava e não consegui devido à burocracia com relação à documentação, preenchimento do questionário socioeconômico (acadêmico de Educação Física).

Não participo, pois é muito burocrático (acadêmico de Sistema de Informação).

Assim inferimos a necessidade dos programas de assistência ter cotas raciais para poder incluir os acadêmicos cotistas, visto que não basta oferecer o acesso, é preciso dar toda assistência e condições para esse acadêmico na universidade. Como afirma Gomes (2005, p. 258), “abrir as portas dos cursos superiores para a juventude negra, é preciso também garantir as condições adequadas de continuidade dos estudos e de formação acadêmica e cientifica".

Destacamos ainda que a desigualdade existente no Brasil acarreta um impedimento para os menos favorecidos, que em sua grande maioria são negros. Desse modo não podemos fazer equiparação entre brancos e negros. Por isso a entrada da população negra na educação superior necessita de atenção, em que as instituições precisam criar mecanismos para garantir a permanência desse acadêmico que está sendo inserido em seu espaço, como afirma Carvalho,

Como se alguém, independentemente das dificuldades que enfrentou, no momento final da competição aberta e feroz, fosse equiparado aos seus 
concorrentes de melhor sorte social. Universalizou-se a concorrência, mas não as condições para competir. Como se um negro se dispusesse a atravessar um rio a nado enquanto um branco andasse de barco a motor em alta velocidade e ao chegarem à outra margem suas capacidades pessoais fossem calculadas apenas pela diferença de tempo gasto na tarefa (2002, p. $18)$.

Cabe ressaltar que como sinaliza Heringer (2013), ao pensar em políticas de permanência é preciso levar em consideração não apenas a permanência material, mas também a simbólica que agrega em seu bojo os fatores subjetivos e interpessoais.

Notamos que a mudança tem acontecido por meio das políticas afirmativas no espaço universitário, porém ainda precisa acontecer essa mudança nos currículos e os aspectos simbólicos serem incluídos na cultura acadêmica que é tão arraigada de valores eurocêntricos, haja vista que os mesmos influenciam de forma positiva como negativa. Talvez esteja aí um dos grandes desafios das universidades.

Segundo Santos (2009, p.159), “permanecer simbolicamente significa para nós a constância do individuo no ensino superior que permita a sua transformação, a partilha com seus pares e o pertencimento ao ambiente universitário". As ações afirmativas oportunizando o negro ser inserido em cursos elizado.

Destacamos que merece uma atenção especial, visto que a cultura eurocêntrica presente em toda a sociedade brasileira é bem aflorada na cultura universitária como afirma uma participante da pesquisa, “E se não fosse a Dilma dar as cotas, onde você estaria?”.

É sabido que quando humilhado o sujeito fica vulnerável a desistência, a subjetividade é afetada. Aqui inferimos a necessidade da quebra da pedagogia decolonial e o currículo monocultural e com urgência repensar um currículo que valorizar e traga a importância de todas as culturas para mudar a realidade de exclusão no espaço universitário.

\section{Permanência material e Permanência simbólica}

Conceituamos permanência material de acordo com Marques (2016, p.1081) são: "todas as atividades relacionadas aos programas de assistência estudantil que se materializam por meia de bolsa que tem por finalidade contribuir financeiramente com os acadêmicos". Aqui citamos o Plano Nacional de Assistência Estudantil (PNAES) que foi criado para garantir a permanência de estudantes de baixa renda matriculados em cursos de graduação presencial das instituições federais de ensino superior, visando a melhorar o desempenho acadêmico e combater situações de repetência e evasão. Implantado em 12 de dezembro de 
2008, é uma das ações oriundas do Plano de Desenvolvimento da Educação - PDE. O Decreto $\mathrm{n}^{\mathrm{o}} 7.234$, de 19 de julho de 2010, regulou o PNAES, traçando os seguintes objetivos:

I - democratizar as condições de permanência dos jovens na educação superior pública federal;

II - minimizar os efeitos das desigualdades sociais e regionais na permanência e conclusão da educação superior;

III - reduzir as taxas de retenção e evasão;

IV - contribuir para a promoção da inclusão social pela educação (BRASIL, 2010b).

Pelo decreto, as IFES devem definir os critérios e a metodologia de seleção dos alunos de graduação a serem beneficiados. O programa, qualificado como política focalizada visa a atender prioritariamente estudantes oriundos da rede pública de educação básica, ou com renda familiar per capita de até um salário mínimo e meio. As ações contemplam os seguintes fatores: "I - moradia estudantil; II - alimentação; III - transporte; IV - atenção à saúde; V - inclusão digital; VI - cultura; VII - esporte; VIII - creche; IX - apoio pedagógico; e $\mathrm{X}$ - acesso, participação e aprendizagem de estudantes com deficiência, transtornos globais do desenvolvimento e altas habilidades e superdotação" (BRASIL, 2010).

Na visão de Menezes a assistência estudantil pode ser traduzida como:

Um mecanismo de direito social que transita por diversas áreas, compreendendo ações que vão desde o acompanhamento das necessidades especiais dos estudantes até o provimento de recursos mínimos (moradia, alimentação, transporte, recursos financeiros) para o alcance dos objetivos de permanência na educação superior. É composta por ações universais elou focalizadas em determinados segmentos com necessidades específicas. Tais ações buscam apoiar a permanência dos estudantes na universidade para que possam concluir sua graduação com bom aproveitamento acadêmico. (2012, p. 73).

No ano de 2013, o MEC lançou o Programa Nacional de Bolsa Permanência (PBP), que visa a conceder auxílio financeiro a estudantes matriculados em instituições federais de ensino superior em situação de vulnerabilidade socioeconômica no montante de $\mathrm{R} \$ 400,00$ (quatrocentos reais). Para estudantes indígenas e quilombolas, é oferecida a quantia diferenciada de $\mathrm{R} \$ 900,00$.

Cabe ressaltar que na UFGD os programas de Assistência Estudantil não têm recorte racial, o que dificulta identificar se o acadêmico ingressante por cotas consegue a inserção. Conforme ressalta Rosa (2015, p. 121): 
[...] a UFGD não possui nenhum programa ou ação voltada aos cotistas e/ou público das ações afirmativas. [...] a instituição ainda não propôs nenhum programa específico para cotista relacionado à assistência, nem ao acompanhamento. Um dos argumentos é que a avaliação socioeconômica já se caracteriza como um perfil de cotistas.

É relevante considerar que existem, além dos aspectos materiais relacionados com a permanência material, fatores subjetivos interpessoais inerentes a cada trajetória, que marcarão de forma diferenciada a permanência dos estudantes no espaço da universidade - a permanência simbólica como já citada acima. A esse respeito, Marques considera que:

A permanência simbólica são todas as situações que não dependem de apoio financeiro ou situações que podem gerar conflitos e resultar em inadaptação e exclusão, bem como os aspectos que não podem ser mensuráveis, mas contribuem para a afiliação ou o fracasso do acadêmico. (2016, p.1081).

Para Coulon (2008, p. 81), “entrar na universidade é explorar e querer voluntariamente mergulhar nos códigos que definem esta organização, códigos estes, frequentemente, opacos ou 'ilegíveis"”.

Para a sua permanência, o estudante precisa lidar com diferentes fatores, entre os quais os fatores de ordem emocional, que podem ser categorizados como: a) fatores pessoais, provenientes de características próprias do estudante; b) fatores interpessoais ou relacionais, referentes ao relacionamento do estudante com seu ambiente, a família e o social; c) fatores acadêmicos, referentes às atividades relacionadas com o ensino-aprendizagem na universidade; d) fatores ambientais, que podem exercer influência negativa ou positiva na adaptação do estudante; e) fatores institucionais, que podem dificultar ou facilitar a adaptação ou a resolução de dificuldades do estudante (TAVARES et al., 2008).

Alguns desses fatores são determinantes para a permanência ou a exclusão da educação superior. No caso do aluno trabalhador, a dupla jornada e a conciliação necessária entre as atividades acadêmicas e o trabalho, como meio de subsistência, podem representar um desafio para que ele tenha êxito em sua trajetória acadêmica. Outro aspecto refere-se ao capital cultural. Segundo Bourdieu (2007, p. 42), “[...] cada família transmite a seus filhos, mais por vias indiretas que diretas, um certo capital cultural”, tal herança cultural aponta como a família tem papel importante na vida do estudante. Dessa forma, os laços familiares, que se definem com maior ou menor grau de responsabilidade, podem influenciar no cotidiano do acadêmico, bem como em seus estudos. Sendo assim, o apoio familiar presente durante os níveis que antecedem a educação superior é fundamental para a permanência do 
acadêmico na universidade; a escolha do curso também pode ser um fator que interfere na permanência do acadêmico na universidade, visto que nessa fase o jovem acadêmico pode se sentir inseguro na escolha do curso.

Muitos escolhem o curso levando em consideração sua pontuação no ENEM ${ }^{2}$, e não o seu desejo de fato (NUNES; VELOSO, 2015). A situação de vulnerabilidade socioeconômica também é um dos fatores que afeta diretamente a permanência do acadêmico na universidade. Segundo pesquisa da FONAPRACE (2010), os dados demostram um contingente de $67,16 \%$ de acadêmicos das IFES pertencentes às classes econômicas B2, C, D e E Desse quantitativo, $44 \%$ pertencem às classes C, D, e E. Cabe ressaltar que $41 \%$ têm renda familiar de no máximo três salários mínimos, ou seja, são estudantes que precisam de algum tipo de apoio institucional para garantir sua permanência na universidade.

Além de todos os fatores elencados acima, que dificultam a permanência do estudante na universidade, Coulon afirma que:

A primeira tarefa que o estudante deve realizar quando ele chega a universidade é aprender o ofício do estudante. Paradoxo objetarão alguns, porque ser estudante é um status social provisório que, diferente de um ofício, dura apenas alguns anos. (2008, p. 31).

$\mathrm{O}$ autor sinaliza que o estudante precisa aprender os códigos que permeiam o espaço universitário. Aprender os códigos, então, "não se trata apenas de adquirir esta competência, é necessário igualmente aprender a maneira de mostrar que eles a possuem”. O estudante, ao ingressar na universidade, precisa, pois, adquirir os status de igual, compreender e decodificar os códigos inerentes à cultura universitária, o que definirá a sua afiliação ou o seu fracasso.

Em se tratando do acadêmico negro ingressante por cotas raciais, em sua maioria, possuem vulnerabilidade socioeconômica. Assim os, fatores que dificultam sua permanência são comuns quando se trata de acadêmicos brancos que possuem a mesma situação. $\mathrm{O}$ racismo, o preconceito, a discriminação racial e o racismo institucional podem representar, todavia, outros fatores que acentuam ainda mais essas dificuldades para os negros.

A discriminação racial é a materialização do racismo e do preconceito que se operacionaliza por meio do tratamento dado a certos grupos de forma a ignorar os seus direitos e a propiciar privilégios ao grupo que se coloca em posição de superioridade. $\mathrm{O}$ racismo, segundo Munanga, seria teoricamente,

${ }^{2}$ O Exame Nacional do Ensino Médio foi criado em 1998, com o objetivo de avaliar o desempenho dos estudantes que estão concluindo ou que já concluíram o ensino médio em anos anteriores. 
[...] uma ideologia essencialista que postula a divisão da humanidade em grandes grupos chamados raças contrastadas que têm características físicas hereditárias comuns, sendo estas últimas suporte das características psicológicas, morais, intelectuais e estéticas e se situam numa escala de valores desiguais. Visto deste ponto de vista, o racismo é uma crença na existência das raças naturalmente hierarquizadas pela relação intrínseca entre o físico e o moral, o físico e o intelecto, o físico e o cultural. O racista cria a raça no sentido sociológico, ou seja, a raça no imaginário do racista não é exclusivamente um grupo definido pelos traços físicos. A raça na cabeça dele é um grupo social com traços culturais, linguísticos, religiosos, etc. que ele considera naturalmente inferiores ao grupo a qual ele pertence. De outro modo, o racismo é essa tendência que consiste em considerar que as características intelectuais e morais de um dado grupo, são consequências diretas de suas características físicas ou biológicas. (2000, p. 24).

O racismo pode ser individual, quando se efetiva pela ação direta de um indivíduo que atua por meio de atos discriminatórios, ou o racismo institucional, que se manifesta por meio de ação ou omissão do Estado e de seus representantes.

No Brasil, tanto o preconceito quanto a discriminação racial produzem efeitos perversos na vida da população negra, os quais se manifestam desde a vida familiar, na infância, na adolescência, na educação e no trabalho (MARQUES, 2010. p.7).

No bojo da luta por igualdade de direitos para a população negra estão presentes elementos que historicamente foram ocultados nas relações sociais, pois apesar de existirem cotidianamente situações que envolvem racismo e preconceitos, ainda há resistência da sociedade brasileira em reconhecer que é racista. As pressões do Movimento Negro Brasileiro foram determinantes para que o Estado aprovasse legislações específicas que coibissem essas ações.

López (2012, p. 126) destaca uma questão importante “[...] que o paradoxo central que colocam estas políticas é o de que instituições públicas tenham de assumir que elas (re) produzem mecanismos de 'racismo institucional' para justificar a execução de políticas de igualdade racial".

Entendemos que, se não houvesse situações de discriminação, preconceito, exclusão, subalternização e invisibilização dos negros no Brasil, não haveria necessidade de tantas políticas públicas de ação afirmativa. Defendemos também que mesmo com elas ainda presenciamos tais situações.

As consequências das relações desiguais e da negação de direitos à população negra forjaram a aparência de normalidade nas relações sociais e nas instituições, tanto públicas quanto privadas, por meio do racismo institucional, que atua 
[...] de forma difusa no funcionamento cotidiano de instituições e organizações, que operam de forma diferenciada na distribuição de serviços, benefícios e oportunidades aos diferentes segmentos da população do ponto de vista racial. Ela extrapola as relações interpessoais e instaura-se no cotidiano institucional. [...] gerando, de forma ampla, desigualdades e iniquidades. (LÓPEZ, 2012, p.127).

$\mathrm{Na}$ educação superior, o racismo institucional pode se efetivar quando as instituições de ensino ignoram que as ações afirmativas democratizam o acesso a estudantes que possuem um novo perfil, os oriundos das camadas populares e vulnerabilidade socioeconômica, e que as suas diferenças fenotípicas, antes ausentes no espaço acadêmico, precisam ser valorizadas.

Outro aspecto latente nas instituições é a negação da urgência de se instituir a comissão avaliadora de autodeclaração, considerando-se a possibilidade de o candidato que se autodeclara preto ou pardo não possuir o fenótipo, o que dependerá exclusivamente de denúncia, caso a instituição não implemente as bancas avaliadoras.

Sob esse aspecto, na UFGD houve um avanço, com a nomeação da comissão que atuará no exame das autodeclarações de candidatos inscritos nas vagas das cotas raciais, nos concursos públicos para docentes, técnicos administrativos e no vestibular institucional. A banca já atuou nos concursos de técnicos administrativos e docentes, mas ainda não foi convocada para atuar na seleção de vestibular.

A negativa de se constituir as bancas com a justificativa de que a Lei 12.711 prevê apenas a autodeclaração, ou de que é difícil identificar quem é negro no Brasil, devido à miscigenação racial, também deve ser refutada, pois cabe à gestão universitária a responsabilidade de garantir a exequibilidade correta da instituição.

É relevante também que a instituição não camufle ou ignore possíveis casos que envolvam discriminação racial com relação a acadêmicos, professores ou servidores. Isso envolve receber denúncias, direta ou indiretamente (ouvidoria), e não tomar as medidas cabíveis, o que resultaria numa forma de racismo institucional.

Há conflitos que ocorrem na sociedade brasileira em relação aos negros, e que podem também se repetir no espaço acadêmico, em decorrência do preconceito, que na visão de Gomes consistem em:

[...] julgamento negativo e prévio dos membros de um grupo racial de pertença, de uma etnia ou de uma religião ou de pessoas que ocupam outro papel social significativo. Esse julgamento prévio apresenta como característica principal a inflexibilidade, pois tende a ser mantido sem levar em conta os fatos que o contestem. Trata-se do conceito ou opinião formados antecipadamente, sem maior ponderação ou conhecimento dos fatos. O 
preconceito inclui a relação entre pessoas e grupos humanos. Ele inclui a concepção que o indivíduo tem de si mesmo e também do outro. (2012, p.54).

A perpetuação do preconceito racial no Brasil revela a existência de um sistema social portador de mecanismos racistas que operam no sentido de manter as desigualdades raciais. Ao enfrentarmos a superação do preconceito, paralelamente combateremos o racismo e a discriminação racial, pois esses três processos se complementam e se retroalimentam. Daí a importância da efetivação das políticas afirmativas desde a educação infantil até a educação superior.

Pode-se verificar, destarte, que se um número significativo de estudantes têm dificuldades para enfrentar o espaço universitário, o estudante negro ao ingressar enfrenta outras adversidades, relativos à discriminação e estereótipos, por ser cotista e por ser negro. Contudo passa a protagonizar num espaço antes hegemonicamente branco e subverte a lógica da colonialidade.

Neste contexto é fundamental que o acadêmico negro aprenda os códigos comuns a todos os estudantes e busque a afiliação nesse novo espaço com intuito de fazer dele o que sinaliza Coulon (2008, p. 41). Por que a permanência simbólica é mais subjetiva e permeia os aspectos da permanência material, razão por que a sutileza do racismo e a discriminação direta ou indireta exigem que o acadêmico negro adote diversas estratégias para permanecer num espaço em que sua presença causa estranheza.

\section{O fortalecimento identitário da população negra}

Quando debatemos sobre a identidade notamos que é evidenciado as características dos sujeitos, em que são exaltadas ou não. Se tratando da identidade negra essa questão é bem negativa, é sabido que permanece a o preconceito de marca na diáspora brasileira, ou seja, as características como cabelo, formato do nariz, tonalidade da cor, boca vão ser determinantes para suscitar a discriminação ou não.

Nesse contexto cabe ressaltar que a construção da identidade implica vários aspectos de ordem social, psicológica, econômica e cultural que fazem parte da realidade de cada sujeito, como afirma Munanga,

A identidade é uma realidade sempre presente em todas as sociedades humanas. Qualquer grupo humano, através do seu sistema axiológico sempre 
selecionou alguns aspectos pertinentes de sua cultura para definir-se em contraposição ao alheio. A definição de si (auto definição) e a definição dos outros (identidade atribuída) têm funções conhecidas: a defesa da unidade do grupo, a proteção do território contra inimigos externos, as manipulações ideológicas por interesses econômicos, políticos, psicológicos, etc. (1994, p.177-178).

Isso indica que a construção da identidade ocorre numa relação dialética, como sinaliza Hall (2006, p.11), "interior e o exterior, entre o mundo pessoal e o mundo público". Destacamos que Hall afirma,

A identidade plenamente unificada, completa, segura e coerente é uma fantasia. Ao invés disso, à medida que os sistemas de significação e representação cultural se multiplicam, somos confrontados por uma multiplicidade desconcertante e cambiante de identidades possível, com cada uma das quais poderíamos nos identificar ao menos temporariamente. (2006, p.13).

Se tratando do negro, então o processo identitário é bem penalizado pela maneira como foi tratado à população negra no Brasil. Segundo Munanga discutir a identidade negra significa compreender que:

[...] esta identidade passa, em seu processo de construção, pela cor da pele. O que significaria que essa identidade tem a ver com a tomada de consciência da diferença biológica entre Brancos e Negros, Amarelos e Negros enquanto grupos. É importante frisar que a negritude embora tenha sua origem na cor da pele negra, não é essencialmente de ordem biológica. De outro modo, a identidade negra não nasce do simples fato de tomar consciência da diferença de pigmentação entre brancos e negros ou negros e amarelos. A negritude ou a identidade negra se refere à história comum que o olhar do mundo ocidental "branco" reuniu sob o nome de negros. (2012, p. 12).

Diante dessa realidade indagamos: Como construir positivamente a identidade de um povo que foi jogado na periferia das cidades, sem nenhuma condição mínima de sobrevivência digna? Como afirmar a identidade num contexto contrário a tudo que se refere à cultura do negro? Como construir a identidade fortalecida diante da desigualdade que foi posto o negro? Como fortalecer a identidade num espaço eurocêntrico?

Sabemos que a construção da identidade acontece com a relação mantida com outro em todos os momentos, como pontua Gomes,

Assim, como em outros processos identitários, a identidade negra se constrói gradativamente, num movimento que envolve inúmeras variáveis, causas e efeitos, desde as primeiras relações estabelecidas no grupo social mais íntimo, no qual os contatos pessoais se estabelecem permeados de 
sanções e afetividades e onde se elaboram os primeiros ensaios de uma futura visão de mundo. (2005, p.43)

Dessa forma construir a identidade significa comungar com seu grupo étnico e através da interação com o outro ir construindo a sua, que é individual, porém muito influenciado pela identidade coletiva, como Munanga afirma,

É uma categoria de definição de um grupo. Esta definição pode ser feita pelo próprio grupo através de alguns atributos selecionados no seu complexo cultural (língua, religião, arte, sistemas político, economia, visão do mundo), de sua história, de seus traços psicológicos letivos, etc., entendidos como mais significativos do que outros e que o diferenciam de demais grupos ou comunidades, religiões, nações, etnias, etc. O que 'nós', antropólogos, chamamos de sinais diacríticos. Trata-se aqui da identidade como categoria de autodefinição ou autoatribuição, que sem dúvida carrega uma carga de subjetividade e de preconceitos em relação aos outros grupos.

(2012, p.9).

Neste contexto a história, a cultura e protagonismo da identidade negra precisa ser resgatada como afirma Munanga,

[...] no processo de construção da identidade coletiva negra, é preciso resgatar sua história e autenticidade, desconstruindo a memória de uma história negativa que se encontra na historiografia colonial ainda presente em "nosso" imaginário coletivo e reconstruindo uma verdadeira história positiva capaz de resgatar sua plena humanidade e autoestima destruída pela ideologia racista presente na historiografia colonial. (2012, p.10).

Observamos o quanto é importante à interação para afirmação da identidade com outro e aquisição de conhecimentos dos processos históricos como pontua o participante da pesquisa,

Então eu procuro participar dos eventos para poder colaborar, de certa forma retribuir o que eu ganhei. Se estou conseguindo afirmar minha identidade cada dia mais, o meu descobrimento de pertencer a um grupo, de pertencimento, e um pertencimento a um grupo de pessoas que sofrem na sociedade por discriminação, por preconceito. Então sempre participei do Neab e de um grupo de estudo por ser uma forma de manifestação e colaboração. (Acadêmico de Educação Física, 2016).

De acordo com o depoimento verificamos que a participação do acadêmico nos eventos do Núcleo de estudos afro-brasileiro da Universidade Federal da Grande Dourados e grupo estudos foi determinante para ir adquirindo conhecimentos e logo possibilitou ao mesmo ir afirmando a sua identidade. 
Nesse contexto verificamos que nem todos os acadêmicos negros participam desses eventos, essas ações são pontuais, o que inferimos que existe uma necessidade de divulgação por parte da universidade para que esses eventos cheguem a todos os acadêmicos, visto que o conhecimento transforma nossas atitudes. Assim inferimos a importância da universidade repensar seus currículos e além disso:

[...] precisamos de fato incorporar as histórias dos outros povos porque na medida em que não temos esse reconhecimento é muito difícil promover um debate qualificado dentro da universidade. Quer dizer na verdade os estudantes chegam com algumas representações de senso comum que temos que desconstruir em sala de aula. (Aguiar, 2016).

Então se faz necessário que a universidade deixe de ser eurocêntrica e branca oportunizando assim que a população negra se sinta de fato inserida nesse espaço e logo possa fortalecer a sua identidade. Visto que muitas vezes como pontua o ex-coordenador do NEAB "porque o que acontece às vezes o individuo entra pelas cotas e ao invés de sair da universidade se reafirmando negro, sai como branco, isso tem a ver com essa dificuldade de reformular a própria concepção que nós temos de universidade”.

E isso acontece porque o negro não se sente inserido, a universidade não lhe oferece meios de fortalecer a sua identidade nesse espaço hegemonicamente branco e que tudo que é diferente a suas características é subjugado como inferior.

Cabe destacar que dar condições de fortalecimento da identidade negra não é tratá-lo como vítima ou mocinho, mas sim é trabalhar em todo âmbito da universidade as diferentes etnias, suas culturas e valores, inclusive da população negra, disseminando bons exemplos e deixando de lado as imagens negativas que são ligadas ao negro.

Outro aspecto que dificuldade o fortalecimento da identidade negra é a invisibilidade do negro em todos os setores da universidade, como sinaliza a participante da pesquisa quando questionado se identificava a presença de outras pessoas negras na Universidade como: docentes, servidores administrativos e alunos. A acadêmica do curso de nutrição responde: "Tenho contato com alguns alunos, porém só tive uma professora negra, além de alguns funcionários da limpeza".

Diante dessa realidade notamos outro aspecto que é a desigualdade social, em que a população negra se encontra inferiorizada e maioria ocupando cargos sem qualificações acadêmicas. 


\section{Considerações Finais}

A democratização do acesso à educação superior representou um avanço muito positivo, porém os sujeitos estudados, além de enfrentarem os problemas comuns a todo acadêmico, tiveram que encarar outros desafios relacionados com a sua posição socioeconômica, a discriminação racial e o racismo institucional.

As políticas afirmativas foram fundamentais para garantir o acesso da população negra na universidade, principalmente em cursos mais concorridos e verificamos o quão é importante que a universidade volte o seu olhar com atenção a permanência desse novo perfil de acadêmico que está sendo inserido na educação superior e propor mecanismos que ofereça a oportunidade do mesmo permanecer até a conclusão do curso.

Elencamos que a permanência material precisa ser resolvida, porém a permanecia simbólica também precisa ter a mesma atenção, pois sabe-se que todos os fatores discriminatórios influenciam diretamente no fortalecimento da identidade, que não é estática e se modifica negativa ou positivamente.

Dessa forma, discutir o fortalecimento da identidade negra perpassa inúmeras condições, entre as quais o respeito ao seu direito à diferença e o reconhecimento a ela devido. Tanto na sociedade quanto na universidade, os espaços de poder são majoritariamente brancos “[...], portanto, a universidade é um espaço de poder. E, por ser um espaço de poder, deve ser um local de disputas, tensões e negociações" (SANTANA, 2010, p. 117).

Nessa perspectiva, fortalecer a identidade negra é romper com estigmas que acompanham o negro desde sempre e coloca o branco como superior, valorizando apenas os padrões eurocêntrico, tanto cultural como estético.

O fortalecimento da identidade negra, portanto, leva o sujeito a, além de assumir suas características fenotípicas, também reconhecer sua história e tudo o que a envolve. É a tomada de consciência de que todos têm direito às oportunidades, indiferentemente de cor/raça. É estar fortalecido para ser negro onde quer que esteja. Alguns entrevistados demonstram ter essa consciência, sabem que é difícil ser reconhecido, porém tem que mostrar sua capacidade intelectual.

Observamos que os acadêmicos envolvidos em eventos e ações que discutem a temática da população negra, e que participam de grupos de estudos da iniciação científica tiveram mais condições de fortalecimento identitário. As disciplinas de Direitos Humanos e Educação das Relações étnico-raciais também contribuíram com aqueles que tiveram a oportunidade de cursá-las. 
Averiguamos, nos depoimentos, que os acadêmicos que participaram dos eventos promovidos pelo NEAB encontraram elementos que contribuíram para o seu fortalecimento identitário. Também notou-se que muitos dos sujeitos participantes da pesquisa não se envolvem porque não conhecem as ações do núcleo.

Observamos vários aspectos favoráveis e desfavoráveis que influenciam o fortalecimento da identidade negra no contexto da educação superior. Elencamos aqui alguns aspectos desfavoráveis, como: o racismo, a invisibilidade do negro, a jornada dupla dos sujeitos, o racismo institucional, a situação socioeconômica dos sujeitos e a falta de debates sobre as cotas na instituição. Dentre os favoráveis revelados na pesquisa, destacamos a participação dos sujeitos nos eventos do NEAB/UFGD, PIVIC e PIBID, o Programa de Assistência Estudantil e as disciplinas referentes aos direitos humanos e relações étnicoraciais.

Salientamos que, apesar das dificuldades enfrentadas pela população negra, as políticas afirmativas têm contribuído para mudar o espaço universitário, com o toque da diversidade, como afirma o depoimento de um acadêmico que respondeu o questionário online: "Pobre não podia fazer Direito, Medicina e Engenharia. Isso era considerado coisa de rico, era o que ouvia até dos meus pais. No máximo era permitido fazer um curso noturno e com as cotas estou na universidade cursando um curso que antes só a elite cursava".

Ressaltamos ainda que, embora as dificuldades enfrentadas pelos sujeitos estudados sejam além das dificuldades comuns a todos os acadêmicos, muitos deles se utilizam das situações para fortalecerem sua identidade com o contato com a história da população negra. Para Munanga (2012), o resgate da história é fator essencial para aumentar a autoestima dos sujeitos pertencentes a esse grupo.

Averiguamos que a identidade, como sinaliza Gomes (2003, p. 41), não é inata, mas se dá na relação com o outro. Nos depoimentos dos participantes da pesquisa, notamos que, quando têm envolvimento com ações que discutem a temática da população negra, grupos de estudos, disciplinas referentes às relações étnico-raciais, PIBIC e PIVIC, eles apresentam uma identidade fortalecida no espaço universitário.

\section{REFERENCIAS}

AGUIAR, Márcio Mucedula. Entrevista dirigida ao Professor Márcio Macedula Aguiar um dos participantes dos debates para implantação das Cotas sociais na UFGD. 2016. 
Entrevista concedida a Maria Aparecida Pereira dos Santos Ribeiro no dia 12 de abril de 2016 nas dependências da UFGD.

BRASIL. Decreto no 7.234, de 19 de julho de 2010. Dispõe sobre o Programa Nacional de Assistência Estudantil - PNAES. Disponível em: <http://www.planalto.gov.br/ccivil_03/_ato 2007-2010/2010/decreto/d7234.htm>. Acesso em: 08 Fev. 2018.

BRASIL. Decreto-Lei $n^{0}$ 5.452, de $1^{\circ}$ de maio de 1943. Aprova a Consolidação das Leis do Trabalho. Disponível em: <http://www.planalto.gov.br/ccivil_03/decreto-lei/Del5452.htm>. Acesso em: 12 mar. 2018.

BRASIL. Lei $\mathbf{n}^{\mathbf{0}}$ 5.465, de 3 de julho de 1968. Dispõe sobre o preenchimento de vagas nos estabelecimentos de ensino agrícola. Disponível em: <http://www.planalto.gov.br/ccivil _03/leis/1950-1969/L5465impressao.htm>. Acesso em: 10 mar. 2018.

BRASIL. Lei $\mathbf{n}^{\mathbf{0}}$ 12.711, de 29 de agosto de 2012. Dispõe sobre o ingresso nas universidades. Disponível em: <http://www.planalto.gov.br/ccivil_03/_ato2011-2014/2012/lei/112711.htm>. Acesso em: 12 mar. 2018.

BRASIL. Instituto Nacional de Estudos e Pesquisas Educacionais Anísio Teixeira - INEP. Censo Escolar da Educação Superior 2010. Brasília: MEC/INEP, 2010. Disponível em: $<$ http://download.inep.gov.br/educacao_superior/censo_superior/resumo_tecnico/resumo_tec nico_censo_educacao_superior_2011.pdf>. Acesso em: 5 mar. 2018.

BOURDIEU, Pierre. A escola conservadora: as desigualdades frente à escola e à cultura. In: NOGUEIRA, Maria Alice; CATANI, Afrânio (Org.). Escritos da educação. 9.ed. Petrópolis: Vozes, 2007.

CARVALHO, José Jorge de. Exclusão racial na universidade brasileira: um caso de ação não negativa. In: Queiroz, Delcele Mascarenhas de. (coord.) O negro na Universidade. Programa a Cor da Bahia / programa de Pós-graduação em Ciências sociais da faculdade de Filosofia e Ciências humanas da UFBA. Salvador: Novos toques, n.5, 2002.

COULON, A. A condição de estudante. A entrada na vida universitária. Tradução de Gaiorgina Gonçalves dos Santos. Sonia Maria R. Sampaio. Salvador, BA: EDUFBA, 2008.

GOMES, Joaquim B. Barbosa. Ação afirmativa e o princípio constitucional da igualdade. Rio de Janeiro: Renovar, 2001.

GOMES, Joaquim B. Barbosa. O debate constitucional sobre ações afirmativas. In: Ação Afirmativa - políticas públicas contra as desigualdades raciais. SANTOS, Renato Emersondos; LOBATO, Fátima (Orgs). Rio de Janeiro: DP\&A, 2003, p. 15-57

GOMES, Joaquim B. Barbosa. A recepção do Instituto de ação afirmativa pelo Direito Constitucional Brasileiro. In Santos, Sales Augusto dos. (org). Ações afirmativas e combate ao racismo nas Américas. Brasília: ministério da educação, Secretaria de Educação Continuada Alfabetização e Diversidade, 2005.

GOMES, Nilma Lino. Alguns termos e conceitos presentes no debate sobre relações raciais no Brasil: Uma breve discussão. In: Educação Anti-racista: caminhos abertos pela Lei 
Federal no 10.639/03. Brasília: MEC, Secretaria de educação continuada e alfabetização e diversidade, 2005, p. 39-62.

HERINGER, Rosana. (2013). O Próximo Passo: as políticas de permanência na universidade pública. In: Paiva, A. R. (org.). Ação Afirmativa em questão. Rio de Janeiro: Pallas.

HALL, S. A Identidade cultural na pós-modernidade. 11. Ed. Rio de Janeiro: DP\&A, 2006.

LÓPEZ, L. C. O conceito de racismo institucional: aplicações no campo da saúde. Interface Comunicação, Saúde, Educação, v. 16, n. 40, p. 121-134, jan./mar., 2012.

MARQUES, Eugenia Portela de Siqueira. ACESSO DE NEGROS E INDÍGENAS NA EDUCAÇÃO SUPERIOR E OS DESAFIOS PARA A PERMANÊNCIA. Anais do XXIV Seminário Nacional UNIVERSITAS/BR. 2016. Disponivel em < http://www.ppe.uem.br/xxivuniversitas/anais/trabalhos/e_5/5-011.pdf > Acesso em 09 de fev. 2018.

MARQUES, Eugenia Portela de Siqueira. O Programa Universidade para Todos e a inserção de negros na educação superior: a experiencia de duas Instituições de Educação Superior de Mato Grosso do Sul - 2005-2008. Tese (Doutorado em Educação). São Carlos: UFSCar, 2010.

MENEZES, S. C. Assistência estudantil na educação superior pública: o programa de bolsas implementado pela Universidade Federal do Rio de Janeiro. Dissertação (Mestrado em Serviço Social) - Pontifícia Universidade do Rio de Janeiro, 2012.

MUNANGA, Kabengele. Identidade, cidadania e democracia: algumas reflexões sobre os discursos anti-racistas no Brasil. In: SPINK, Mary Jane Paris(Org.). A cidadania em construção: uma reflexão transdisciplinar. São Paulo: Cortez, 1994, p. 177-187.

MUNANGA, Kabengele. Negritude e identidade negra ou afrodescendente: um racismo ao avesso? Revista da ABPN, v. 4, n. 8, p. 6-14, jul./out., 2012. Disponível em: http://abpnrevista.org.br/revista/index.php/revistaabpn1/article/view/246. Acesso em: $07 \mathrm{fev}$. 2018.

MUNANGA, Kabengele. Uma abordagem conceitual das noções de raça, racismo, identidade e etnia. In: BRANDÃO, André Augusto P. Programa de educação sobreo negro na sociedade brasileira. Niterói: EDUFF, 2000.

NUNES, Roseli Souza dos Reis; VELOSO, Tereza Christina Mertens Aguiar. Elementos que interferem na permanência do estudante na educação superior pública. XXIII SEMINÁRIO NACIONAL DA REDE UNIVERSITAS/Br - Políticas da educação superior no Brasil: A expansão privado-mercantil em questão. Anais... Universidade Federal do Pará, 20 a 23 de maio, p. 815-830, 2015.

ROSA, Aline Anjos da. A implementação das cotas raciais e sociais na UFGD e sua contribuição para a política de ações afirmativas ( 2012-2014). Dissertação (Mestrado em Educação) - Universidade Federal da Grande Dourados, Dourados, 2015 
SANTANA, Renato Oliveira. Efeitos da educação superior nas identidades de negros cotistas da Universidade Estadual de Mato Grosso do Sul, 2010. Disponível em:

http://www3.ucdb.br/mestrados/arquivos/dissert/742.pdf; acessado em: 21 de mar. de 2018.

SANTOS, Dayane Brito Reis. Para Além das Cotas: A Permanência de Estudantes Negros no Ensino Superior Como Política de Ação Afirmativa. Tese (Doutorado em Educação). Universidade Federal da Bahia, 2009.

TAVARES, Marcelo et al. Apoio psicológico e social a estudantes nas universidades brasileiras. In: KULLMANNET et al. (Orgs). Apoio estudantil: reflexões sobre o ingresso e permanência no ensino superior. UFSM: Santa Maria, 2008.

\section{$\underline{\text { SOBRE AS AUTORAS }}$}

\section{Eugenia Portela de Siqueira Marques}

Doutora em Educação pela Universidade Federal de São Carlos (UFSCar). Vice-Diretora da FAED/UFGD. Professora do Programa de Pós-graduação em Educação da Universidade Federal da Grande Dourados (UFGD). Líder do Grupo de Estudos e Pesquisas sobre Educação, Relações Étnico-Raciais e Formação de Professores (GEPRAFE/UFGD) e membro do Núcleo de Estudos Afro-brasileiros (NEAB/UFGD). E-mail. Eumar13@ @erra.com.br

\section{Maria Aparecida Pereira dos Santos Ribeiro}

Mestre em Educação pela Universidade Federal da Grande Dourados (UFGD). Professora Formadora da Coordenadoria Regional de Educação. Membro do Grupo de Estudos e Pesquisas sobre Educação, Relações Étnico-Raciais e Formação de Professores (GEPRAFE/UFGD). E-mail: mpr.2010@hotmail.com 